\title{
Efficiency measurement of two-stage processes with shared inputs and outputs by DEA: An application on Malaysian Palm Oil refineries
}

\author{
Ali Ashrafi
}

\begin{abstract}
In recent years, a great number of Data Envelopment Analysis (DEA) studies have focused on Decision Making Units (DMUs) with two-stage structures, where all outputs from the first stage are intermediate products that are applied as the inputs of the second stage. In many situations, some inputs and outputs are shared between two stages. For this type of two-stage process, the conventional two-stage DEA models have some limitations e.g. efficiency formulation and linearizing transformation. In this paper, we introduce a relational DEA model for the two-stage process with shared inputs and outputs that the overall efficiency is illustrated as a convex combination of efficiencies of its two stages. The linearity of DEA models is preserved in our model. A numerical example of Malaysian Palm Oil refineries is used to explain the model.
\end{abstract}

Keywords - data envelopment analysis; efficiency; two-stage; intermediate product; shared inputs and outputs.

\section{Introduction}

As a non-parametric technique, Data Envelopment Analysis (DEA) was first introduced by Charnes et al. [6] for evaluating the relative efficiency of peer production systems or decision making units (DMU), which have multiple inputs and outputs. In recent years, a great number of DEA studies have concentrated on two-stage production systems, where all outputs from the first stage are intermediate products which have been used as the inputs of the second stage. For example, Seiford and Zhu [12] improved a two-stage DEA approach for measuring the efficiency of the profitability and marketability of US commercial banks. Zhu [16] assessed the financial efficiency of the best 500 companies by applying the same two-stage process while Sexton and Lewis [13] studied the Major League Baseball performance in a two-stage process. Chen and Zhu [7] developed a linear DEA type model where the efficiency of each stage is defined on its own production possibility set. Kao and Hwang [11] developed a different approach where the overall efficiency of the system can be decomposed into the product of the efficiencies of the twostages. Chen et al. [8] presented a model similar to the Kao and Hwang model, but in an additive form. Wang and Chin [14] suggested some alternative relational DEA models for two-stage processes. They proposed a two-stage DEA model in a way that the overall efficiency of the whole process is modeled as the weighted harmonic mean of the individual efficiencies in the two stages.

Ali Ashrafi: Faculty of Mathematics, Statistics and Computer Science, Semnan University,

Semnan, Iran.
Actually, in some situations, DMUs can have a twostage structure with shared inputs and outputs. In this case, the DMU cannot make decisions about dedicating its inputs or outputs among its stages to maximize its efficiency. More recently, Zha and Liang [15] have introduced a non-linear approach to determine the efficiency of two-stage production systems with shared flows, where the inputs of the system can be freely allocated between two stages. Via assuming one of the efficiencies of the stages as a parameter, their non-linear approach was changed into a parametric linear model. One of the main restrictions in the proposed model by Zha and Liang [15] is that it can only be applied to Constant Returns to Scale (CRS) cases.

In this paper, we develop a relational DEA model for two-stage processes with shared inputs and outputs in order to measure the efficiency of the whole system and the efficiencies of the two stages at the same time. The proposed model takes into account the series relationship among the two stages. Under the new framework, the overall efficiency of the system is illustrated as a convex combination of efficiencies of its two stages. Unlike Zha and Liang's model [15], the proposed approach can be used under both CRS and Variable Returns to Scale (VRS). The two-stage production process with shared inputs of the Palm Oil refineries in Malaysia is used to illustrate the new proposed model.

The rest of this paper is organized as follows: Section II provides a background of basic DEA models. In Section III, we first present a general two-stage process with sharing inputs and outputs and then develop a relational DEA model for measuring the efficiencies of the whole system as well as the two stages. Section V applies the new approach to Processed Palm Oil (PPO) industry in Malaysia. Finally, conclusions are provided in the last section.

\section{Background}

Let $x_{i j},(i=1, \ldots, m)$ and $y_{r j},(r=1, \ldots, s)$ represent the $i$ th input, and $r$ th output of $\mathrm{DMU}_{j},(j=1, \ldots, n)$. If $\bar{v}_{i}$ and $\bar{u}_{r}$ be the known cost and price associated with inputs $i$ and outputs, $r$ respectively, then the relative efficiency score of the specific $\mathrm{DMU}_{o}$, can be expressed as the ratio of the weighted outputs to the weighted inputs:

$$
\text { Efficiency }=\frac{\text { weighted sum of outputs }}{\text { weighted sum of inputs }}=\frac{\sum_{r=1}^{s} \bar{u}_{r} y_{r o}}{\sum_{i=1}^{m} \bar{v}_{i} x_{i o}} \text {. }
$$

In the absence of known multipliers, Charnes et al. [6] proposed a Fractional Programming (FP) problem (ratio DEA model) in order to derive appropriate multipliers for a 
given DMU. The ratio DEA model that is also known as the CCR model for evaluating the relative efficiency of $\mathrm{DMU}_{o}$ can be indicated as follows:

$$
\begin{aligned}
E_{o}^{*}=\max & \frac{\sum_{r=1}^{s} \bar{u}_{r} y_{r o}}{\sum_{i=1}^{m} \bar{v}_{i} x_{i o}} \\
\text { s.t. } & \frac{\sum_{r=1}^{s} \bar{u}_{r} y_{r j}}{\sum_{i=1}^{m} \bar{v}_{i} x_{i j}} \leq 1, j=1, \ldots, n, \\
& \bar{u}_{r}, \bar{v}_{r} \geq 0, r=1, \ldots, s, i=1, \ldots, m,
\end{aligned}
$$

The constraints indicate that the efficiency of each DMU should not exceed one. The aim is calculating weights $\bar{v}_{i}$ and $\bar{u}_{r}$ that maximize the efficiency of $\mathrm{DMU}_{o}$. According to the constraints of model (2), the optimal objective value $E_{o}^{*}$ is at most one. $E_{o}^{*}=1$ implies the efficient DMU and $E_{o}^{*}<1$ shows the inefficient one.

Through applying the Charnes-Cooper transformation [5], the FP problem (2) can be converted into a linear programming (LP) problem. Specifically, make the transformation $\left[\sum_{i=1}^{m} \bar{v}_{i} x_{i o}\right]^{-1}=t$ and set $u_{r}=t \bar{u}_{r},(r=1, \ldots, s)$ and $\boldsymbol{v}_{\boldsymbol{i}}=\boldsymbol{t} \overline{\boldsymbol{v}}_{\boldsymbol{i}},(\boldsymbol{i}=\mathbf{1}, \ldots, \boldsymbol{m})$. Then model (2) can be reflected in the following form:

$$
\begin{aligned}
E_{o}^{*}=\max & \sum_{r=1}^{s} u_{r} y_{r o} \\
\text { s.t. } & \sum_{i=1}^{m} v_{i} x_{i o}=1, \\
& \sum_{r=1}^{s} u_{r} y_{r j}-\sum_{i=1}^{m} v_{i} x_{i j} \leq 0, j=1, \ldots, n, \\
& u_{r}, v_{i} \geq 0, r=1, \ldots, m, i=1, \ldots, s .
\end{aligned}
$$

To evaluate the efficiency score of all DMUs, this model will be solved for $n$ times, once for each DMU. Each DMU selects input and output weights in such a way that it maximizes its efficiency score. Note that the CCR model is developed in the assumption of CRS of DMUs. For the long-run analysis, Banker, Charnes and Cooper (BCC) [3] extended the CCR model by providing for the VRS. The BCC model estimates the efficiency of DMUs and identifies whether a DMU is operating in increasing, decreasing or constant returns to scale. The $\mathrm{BCC}$ model for evaluating the efficiency of $\mathrm{DMU}_{o}$ is given by following LP problem:

$$
\begin{aligned}
E_{o}^{*}=\max & \sum_{r=1}^{s} u_{r} y_{r o}+\delta \\
\text { s.t. } & \sum_{i=1}^{m} v_{i} x_{i o}=1, \\
& \sum_{r=1}^{s} u_{r} y_{r j}+\delta-\sum_{i=1}^{m} v_{i} x_{i j} \leq 0, j=1, \ldots, n, \\
& u_{r}, v_{i} \geq 0, r=1, \ldots s, i=1, \ldots, m,
\end{aligned}
$$

$\delta$ free.

\section{A relational DEA model for two-stage processes with shared inputs and outputs}

Now, consider a production system composed of a twostage process with shared inputs and outputs as shown in Figure 1. Suppose that there is a set of $\mathrm{n}$ DMUs denoted by $D M U j(j=1, \ldots, n)$. Each DMUj has $m$ inputs, $s$ outputs and $D$ intermediate products. These Inputs (outputs) are divided to three parts:

(1) only inputs (outputs) of the first stage;

(2) only inputs (outputs) of the second stage;

(3) the shared inputs (outputs) of both stages.

For each $\mathrm{DMU}_{j}$, we define the following notations:

$x_{i j}^{(1)}, i \in I_{1}$ : the inputs of the first stage;

$x_{i j}^{(2)}, i \in I_{2}$ : the inputs of the second stage;

$x_{i j}^{(s)}, i \in I_{3}$ : the shared inputs between two stages;

$z_{d j}, d \in M$ : the intermediate products generated by the first stage and utilized by the second stage;

$y_{r j}^{(1)}, r \in O_{1}$ : the outputs of the first stage,

$y_{r j}^{(2)}, r \in O_{2}$ : the outputs of the second stage,

$y_{r j}^{(s)}, r \in O_{3}$ : the shared outputs between two stages,

$\alpha_{i}, i \in I_{3}$ : the portion of the shared input $i$ allocated to the first stage,

$\beta_{r}, r \in O_{3}$ : the portion of the shared output $\mathrm{r}$ attributed to the first stage,

Where $I_{1} \cup I_{2} \cup I_{3}=\{1, \ldots, m\}, \quad O_{1} \cup O_{2} \cup O_{3}=\{1, \ldots, s\}$ and $M=\{1, \ldots, D\}$.

Note that $\alpha_{i}, i \in I_{3}$ and $\beta_{r}, r \in O_{3}$ are decision variables that must be determined.

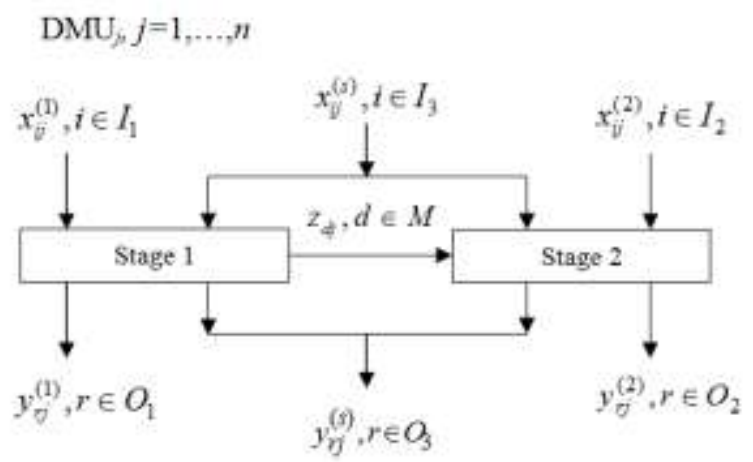

Figure 1. Two-stage process with Shared Inputs and Outputs Consider $\mathrm{DMU}_{o}(o \in\{1, \ldots, n\})$ be the DMU under evaluation. Based on the CCR model, the efficiency scores of the whole process and the two individual stages of $\mathrm{DMU}_{o}$ under the CRS assumption can be calculated as follows: 


$$
\begin{aligned}
& E_{o}=\frac{A}{B}, \\
& A=\sum_{r \in O_{1}} u_{r}^{(1)} y_{r o}^{(1)}+\sum_{r \in O_{2}} u_{r}^{(2)} y_{r o}^{(2)}+\sum_{d \in M} \eta_{d}^{(1)} z_{d o}+ \\
& \sum_{r \in O_{3}} u_{r}^{(s)} \beta_{r} y_{r o}^{(s)}+\sum_{r \in O_{3}} \tilde{u}_{r}^{(s)}\left(1-\beta_{r}\right) y_{r o}^{(s)}, \\
& B=\sum_{i \in I_{1}} v_{i}^{(1)} x_{i o}^{(1)}+\sum_{i \in I_{2}} v_{i}^{(2)} x_{i o}^{(2)}+\sum_{i \in I_{3}} v_{i}^{(s)} \alpha_{i} x_{i o}^{(s)}+ \\
& \sum_{i \in I_{3}} \tilde{v}_{i}^{(s)}\left(1-\alpha_{i}\right) x_{i o}^{(s)}+\sum_{d \in M} \eta_{d}^{(2)} z_{d o}, \\
& E_{o}^{(1)}=\frac{\sum_{r \in O_{1}} u_{r}^{(1)} y_{r o}^{(1)}+\sum_{d \in M} \eta_{d}^{(1)} z_{d o}+\sum_{r \in O_{3}} u_{r}^{(s)} \beta_{r} y_{r o}^{(s)}}{\sum_{i \in I_{1}} v_{i}^{(1)} x_{i o}^{(1)}+\sum_{i \in I_{3}} v_{i}^{(s)} \alpha_{i} x_{i o}^{(s)}} \\
& E_{o}^{(2)}=\frac{\sum_{r \in O_{2}} u_{r}^{(2)} y_{r o}^{(2)}+\sum_{r \in O_{3}} \tilde{u}_{r}^{(s)}\left(1-\beta_{r}\right) y_{r o}^{(s)}}{\sum_{i \in I_{2}} v_{i}^{(2)} x_{i o}^{(2)}+\sum_{d \in M} \eta_{d}^{(2)} z_{d o}+\sum_{i \in I_{3}} \tilde{v}_{i}^{(s)}\left(1-\alpha_{i}\right) x_{i o}^{(s)}},
\end{aligned}
$$

$v_{i}^{(1)}, v_{i}^{(2)}, v_{i}^{(s)}, \tilde{v}_{i}^{(s)}, u_{r}^{(1)}, u_{r}^{(2)}, u_{r}^{(s)}, \tilde{u}_{r}^{(s)}, \eta_{d}^{(1)}$ and $\eta_{d}^{(2)}$ unknown non-negative multipliers. Note that $\eta_{d}^{(1)}$ can be equal to $\eta_{d}^{(2)}$.

Note that similar to Ref. [1], for evaluating the overall efficiency score, we have assumed the whole process as a single process such that the intermediate products serve as both inputs and outputs at the same time.

In an effort to estimate the overall efficiency of the $\mathrm{DMU}_{o}$, taking into account the series relationship among two stages, we formulate the following FP problem:

$$
\begin{aligned}
E_{o}^{*}=\max & E_{o} \\
\text { s.t. } & E_{j}^{(1)} \leq 1, j=1, \ldots, n, \\
& E_{j}^{(2)} \leq 1, j=1, \ldots, n, \\
& \eta_{d}^{(1)}=\eta_{d}^{(2)}=\eta_{d}, d \in M, \\
& v_{i}^{(1)}, v_{i}^{(2)}, v_{i}^{(s)}, \tilde{v}_{i}^{(s)}, u_{r}^{(1)}, u_{r}^{(2)}, u_{r}^{(s)}, \tilde{u}_{r}^{(s)}, \eta_{d} \geq 0, \forall i, r, d, \\
& 0 \leq \alpha_{\mathrm{i}}, \beta_{r} \leq 1, \forall i, r .
\end{aligned}
$$

Note that similar to Refs. $[8,11]$, in model $(6)$, the assumption is that every intermediate product has the same multiplier, no matter whether it plays the role of input or output.

Definition 1. If the optimal solution of model (6) satisfies $\boldsymbol{E}_{o}^{*}=\mathbf{1}$, then $\mathrm{DMU}_{o}$ is called overall efficient.

Definition 2. If the optimal solution of model (6) satisfies $\boldsymbol{E}_{\boldsymbol{o}}^{(\mathbf{1})^{*}}=\mathbf{1}\left(\boldsymbol{E}_{\boldsymbol{o}}^{(\mathbf{2})^{*}}=\mathbf{1}\right)$, then $\mathrm{DMU}_{o}$ is efficient in its first (second) stage.

Theorem 1. In model (6), the overall efficiency $E_{o}$ is a convex combination of the efficiencies of two individual stages, $E_{o}^{(1)}$ and $E_{o}^{(2)}$.

As a consequence of this theorem, we conclude that $\mathrm{DMU}_{o}$ is overall efficient if and only if it is efficient in its two stages.

It must be mentioned that through applying the CharnesCooper transformation [5] and by introducing new variables, the model (6) can be transformed into a linear LP problem.
The solution of the model (6) will be performed for $n$ times, once for each DMU to assess the overall efficiency scores of the systems. On optimality, also the efficiency scores of two stages of each $\operatorname{DMU}_{o}(o=1, \ldots, n)$, can be calculated .

So far the discussion has been based upon the assumption of CRS. Now the proposed model for the variable returns to scale (VRS) case is extended. Based on the BCC model, the VRS efficiency of $\mathrm{DMU}_{o}$ in the first and second stages can be expressed as follows:

$$
\begin{aligned}
& E_{o}^{(1)}=\frac{\sum_{r \in O_{1}} u_{r}^{(1)} y_{r o}^{(1)}+\sum_{d \in M} \eta_{d}^{(1)} z_{d o}+\sum_{r \in O_{3}} u_{r}^{(s)} \beta_{r} y_{r o}^{(s)}+\delta^{1}}{\sum_{i \in I_{1}} v_{i}^{(1)} x_{i o}^{(1)}+\sum_{i \in I_{3}} v_{i}^{(s)} \alpha_{i} x_{i o}^{(s)}}, \\
& E_{o}^{(2)}=\frac{\sum_{r \in O_{2}} u_{r}^{(2)} y_{r o}^{(2)}+\sum_{r \in O_{3}} \tilde{u}_{r}^{(s)}\left(1-\beta_{r}\right) y_{r o}^{(s)}+\delta^{2}}{\sum_{i \in I_{2}} v_{i}^{(2)} x_{i o}^{(2)}+\sum_{d \in M} \eta_{d}^{(2)} z_{d o}+\sum_{i \in I_{3}} \tilde{v}_{i}^{(s)}\left(1-\alpha_{i}\right) x_{i o}^{(s)}},
\end{aligned}
$$

where the variables $\delta^{1}$ and $\delta^{2}$ are free in sign.

Accordingly, the overall efficiency of $\mathrm{DMU}_{o}$ under VRS assumption can be defined as follows:

$$
E_{o}^{*}=\max \frac{A}{B}
$$

$$
\begin{array}{ll}
\text { s.t. } A & =\sum_{r \in O_{1}} u_{r}^{(1)} y_{r o}^{(1)}+\sum_{d \in M} \eta_{d}^{(1)} z_{d o}+\sum_{r \in O_{3}} u_{r}^{(s)} \beta_{r} y_{r o}^{(s)}+\delta^{1}+ \\
& \sum_{r \in O_{2}} u_{r}^{(2)} y_{r o}^{(2)}+\sum_{r \in O_{3}} \tilde{u}_{r}^{(s)}\left(1-\beta_{r}\right) y_{r o}^{(s)}+\delta^{2}, \\
& B=\sum_{i \in I_{1}} v_{i}^{(1)} x_{i o}^{(1)}+\sum_{i \in I_{2}} v_{i}^{(2)} x_{i o}^{(2)}+\sum_{i \in I_{3}} v_{i}^{(s)} \alpha_{i} x_{i o}^{(s)}+ \\
& \sum_{i \in I_{3}} \tilde{v}_{i}^{(s)}\left(1-\alpha_{i}\right) x_{i o}^{(s)}+\sum_{d \in M} \eta_{d}^{(2)} z_{d o} \\
& \frac{\sum_{r \in O_{1}} u_{r}^{(1)} y_{r o}^{(1)}+\sum_{d \in M} \eta_{d}^{(1)} z_{d o}+\sum_{r \in O_{3}} u_{r}^{(s)} \beta_{r} y_{r o}^{(s)}+\delta^{1}}{\sum_{i \in I_{1}} v_{i}^{(1)} x_{i o}^{(1)}+\sum_{i \in I_{3}} v_{i}^{(s)} \alpha_{i} x_{i o}^{(s)}} \leq 1, \forall j, \\
& \frac{\sum_{r \in O_{2}} u_{r}^{(2)} y_{r o}^{(2)}+\sum_{r \in O_{3}} \tilde{u}_{r}^{(s)}\left(1-\beta_{r}\right) y_{r o}^{(s)}+\delta^{2}}{\sum_{i \in I_{2}} v_{i}^{(2)} x_{i o}^{(2)}+\sum_{d \in M} \eta_{d}^{(2)} z_{d o}+\sum_{i \in I_{3}} \tilde{v}_{i}^{(s)}\left(1-\alpha_{i}\right) x_{i o}^{(s)}} \leq 1, \forall j, \\
& \eta_{d}^{1}=\eta_{d}^{2}=\eta_{d}, d=1, \ldots, D, \\
& v_{i}^{(1)}, v_{i}^{(2)}, v_{i}^{(s)}, \tilde{v}_{i}^{(s)}, u_{r}^{(1)}, u_{r}^{(2)}, u_{r}^{(s)}, \tilde{u}_{r}^{(s)}, \eta_{d} \geq 0, \forall i, r, d, \\
& 0 \leq \alpha_{i}, \beta_{r} \leq 1, \forall i, r . \\
& \delta^{1}, \delta^{2} \text { free. }
\end{array}
$$

By following the method proposed for CRS condition and by introducing the same variation for variables, overall efficiency and the efficiency scores of the two stages of DMUo under VRS assumption can be calculated.

After solving the above model, as in CRS case, the efficiency scores of the two stages under the assumption of VRS can be evaluated as follows: 


\section{Malaysian processed palm oil (PPO) industry}

Malaysia is the most important PPO producer and exporter in the world. The whole production process of the PPO industry can be divided into two stages: refining and fractionating. In the first stage, the refinery transforms the Crude Palm Oil (CPO) to Refined Bleached Deodorized Palm Oil (RBDPO) and Palm Fatty Acid Distillate (PFAD). The PFAD as the output of the refining stage is supplied directly to the market. Although RBDPO also could be sold directly in the market, considerable volume of produced RBDPO is usually used as an intermediate product and is fractionated to Refined Bleached Deodorized Olein (RBD Olein) and Refined Bleached Deodorized Stearin (RBD Stearin) in the second stage. The inputs of the system are CPO, Labor and Capital and total utility (aggregated cost on water, electricity and fuel). The total declared refining loss of CPO in the refining stage for all firms is less than 1 percent; i.e. they are using the CPO efficiently in the system. Furthermore, some of the refineries use CPO as the feedstock of the refining stage while others apply low quality RBDPO as the feedstock and just refine it in order to make it suitable to be used in the fractionation stage. Henceforth, due to these kinds of differences between feedstock of the refineries, this study opts to concentrate on Capital cost, Labor and total utility as the inputs of the system, which are shared in both stages of the production process. It means that we do not know how much of these inputs exactly are dedicated to each stage of production.

In this paper, we use the proposed approach under the VRS assumption to measure the efficiency of the 25 Malaysian Palm Oil refineries in years 2006 to 20 09. The inputs of the system, which are shared to both stages, are:

Labor $\left(x_{1}^{(s)}\right)$ : number of employees in persons,

Capital cost $\left(x_{2}^{(s)}\right)$ : The capital cost in each year is calculated based on declared volume of total assets in thousand Ringgit Malaysia (RM) as: capital cost =total assets* (long term government bond rate + depreciation rate),

Total utility $\left(x_{3}^{(s)}\right)$ : Total payment of the refineries for water, electricity and energy during each year in thousand RM.

The outputs of the first stage, which are not passed to the second stage, are:

Refined Bleached Deodorized palm oil (RBDPO) ( $\left.y_{1}^{(1)}\right)$ : part of RBDPO sold in the market directly in Tons,

Palm Fatty Acid Distillate (PFAD) $\left(y_{2}^{(1)}\right)$ : Supplied to the market in Tons.

The intermediate product, which is output of the first stage as well as input of the second stage, is:

Refined Bleached Deodorized palm oil (RBDPO) $\left(z_{1}\right)$ : part of RBDPO passed to second stage in Tons,

The outputs of the second stage are:

Refined Bleached Deodorized Palm Stearin RBD Stearin $\left(y_{1}^{(2)}\right)$ : in Tons,
Refined Bleached Deodorized Olein Palm oil (RBD Olein) $\left(y_{2}^{(2)}\right)$ : in Tons.

In Table 1 we present basic statistics for input and output variables in years 2006-2009: mean, standard deviation, minimum and maximum value.

Table 1. Data set of the 25 palm oil refineries in years 2006 to 2009.

\begin{tabular}{|c|c|c|c|c|c|c|}
\hline \multirow{2}{*}{ ह } & & \multicolumn{3}{|c|}{ Shared inputs } & \multicolumn{2}{|c|}{$\begin{array}{c}\text { First stage } \\
\text { outputs }\end{array}$} \\
\hline & & $x_{1}^{(s)}$ & $x_{2}^{(s)}$ & $x_{3}^{(s)}$ & $y_{1}^{(1)}$ & $y_{2}^{(1)}$ \\
\hline \multirow{4}{*}{ సั } & Mean & 11.57 & 344064.70 & 9207.10 & 14440.19 & 16662.90 \\
\hline & St. Dev. & 1.43 & 400970.70 & 14257.40 & 25655.81 & 7532.75 \\
\hline & Max. & 12.00 & 1754601.80 & 45026.90 & 103935.00 & 38578.00 \\
\hline & Min. & 6.00 & 362.90 & 555460.00 & 0.00 & 262.00 \\
\hline \multirow{4}{*}{ సิ } & Mean & 11.61 & 7256.60 & 8811.30 & 29337.43 & 21386.00 \\
\hline & St. Dev. & 1.37 & 7197.70 & 14243.10 & 29870.51 & 26598.02 \\
\hline & Max. & 12.00 & 32339.60 & 45858.10 & 89308.00 & 137280.00 \\
\hline & Min. & 6.00 & 90.50 & 703.20 & 0.00 & 273.00 \\
\hline \multirow{4}{*}{ స్ } & Mean & 11.28 & 7617.00 & 10104.50 & 47488.04 & 18059.56 \\
\hline & St. Dev. & 1.79 & 7013.30 & 15513.70 & 78219.41 & 9796.26 \\
\hline & Max. & 12.00 & 32929.20 & 46283.20 & 386305.00 & 47628.00 \\
\hline & Min. & 6.00 & 570.80 & 770.50 & 0.00 & 283.00 \\
\hline \multirow{4}{*}{ สิे } & Mean & 11.28 & 7578.90 & 10344.40 & 35237.96 & 18390.88 \\
\hline & St. Dev. & 1.79 & 6751.40 & 15659.10 & 33658.05 & 10683.38 \\
\hline & Max. & 12.00 & 31638.90 & 45463.20 & 160524.00 & 52900.00 \\
\hline & Min. & 6.00 & 565.40 & 767.70 & 0.00 & 275.00 \\
\hline
\end{tabular}

\begin{tabular}{clll}
\hline $\begin{array}{c}\text { Intermediate } \\
\text { Product }\end{array}$ & & \multicolumn{2}{c}{$\begin{array}{c}\text { Second stage } \\
\text { outputs }\end{array}$} \\
\cline { 1 - 1 }$z_{1}$ & & \multicolumn{1}{c}{$y_{1}^{(2)}$} & \multicolumn{1}{c}{$y_{2}^{(2)}$} \\
\hline 363186.48 & & 77334.76 & 285851.71 \\
129762.38 & & 28915.13 & 103555.07 \\
551124.00 & & 137781.00 & 413343.00 \\
6222.00 & & 1464.00 & 4758.00 \\
\hline 344703.83 & & 71582.87 & 273120.96 \\
144027.68 & & 29498.84 & 119243.86 \\
612360.00 & & 153090.00 & 496777.00 \\
6455.00 & & 1484.00 & 4971.00 \\
\hline 352938.60 & & 76655.72 & 276282.88 \\
160950.00 & & 32599.17 & 133600.57 \\
680400.00 & & 170100.00 & 541375.00 \\
6690.00 & 1538.00 & 5152.00 \\
\hline 377227.16 & 74426.08 & 302801.08 \\
157795.65 & 35436.78 & 127159.59 \\
756000.00 & 189000.00 & 567000.00 \\
6553.00 & 1542.00 & 5011.00 \\
\hline
\end{tabular}

The efficiency of the whole system, for each refinery, is calculated by applying model (8) while the efficiency of each stage is estimated by using equation (7). The result of the model is reflected in Table 2. In the years 2007 and 2006, data on some of the firms are not available, so no estimation of the efficiency rate for some refineries could be done. The firms 24 and 25 commencement year is 2007, so data for these two firms in 2006 are not available and firm 10 has not revealed data about the total utility cost in years 2006 and 2007. Based on the result, not surprisingly, the estimated average efficiency rate of the Malaysian palm oil refineries is rather high (more than 80\%). According to classical international trade theories, the efficiency rate of an industry in a country is a proxy of competitiveness of this country in the world market. The rather high estimated efficiency rate of the Malaysian PPO industry is a reasonable cause for Malaysia being the largest producer and exporter of PPO in the world.

The estimated efficiency rate of the industry has increased from $83 \%$ in year 2006 to $88 \%$ in 2009 , which can 
Proc. of The Fifth Intl. Conf. On Advances in Applied Science and Environmental Engineering - ASEE 2016

Copyright (C) Institute of Research Engineers and Doctors, USA .All rights reserved.

ISBN: 978-1-63248-086-6 doi: 10.15224/ 978-1-63248-086-6-59

be a sign of the technological progress in the industry. The inefficiency of the firms in the Malaysian PPO industry is mostly attributed to the refining stage, which transforms CPO to RBDPO and PFAD. The efficiency rate in the refining stage increased from $73 \%$ in 2006 to $82 \%$ in 2009. On the other hand, the performance of most refineries has been efficient in the fractionation stage while the average rate of efficiency in this stage has slightly decreased from 99 $\%$ in 2006 to $98 \%$ in 2009.

Table 2. Efficiency Scores for 25 palm oil refineries in years 2006 to 2009

\begin{tabular}{|c|c|c|c|c|c|c|}
\hline \multirow[t]{2}{*}{$\mathrm{DMU}$} & \multicolumn{3}{|c|}{2006} & \multicolumn{3}{|c|}{2007} \\
\hline & Whole & Stage 1 & Stage 2 & Thole & Stage 1 & Stage? \\
\hline 1 & 0.660 & 0.493 & 1.000 & 0.627 & 0.474 & 0.775 \\
\hline 2 & 0.760 & 0.658 & 1.000 & 0.691 & 0.596 & 1.000 \\
\hline 3 & 0.899 & 0.837 & 0.974 & 0.831 & 0.758 & 1.000 \\
\hline 4 & 0.899 & 0.831 & 1.000 & 0.881 & 0.419 & 0.949 \\
\hline 5 & 0.682 & 0.517 & 1.000 & 0.655 & 0.539 & 0.816 \\
\hline 6 & 0.912 & 0.867 & 1.000 & 1.00 & 1.00 & 1.000 \\
\hline 7 & 1.000 & 1.000 & 1.000 & 1.00 & 1.00 & 1.000 \\
\hline 8 & 0.960 & 0.907 & 1.000 & 1.00 & 1.00 & 1.000 \\
\hline 9 & 1.000 & 1.000 & 1.000 & 0.947 & 0.911 & 0.967 \\
\hline 10 & - & - & - & - & - & - \\
\hline 11 & 0.853 & 0.775 & 1.000 & 0.997 & 0.991 & 0.997 \\
\hline 12 & 0.911 & 0.833 & 1.000 & 0.895 & 0.835 & 1.000 \\
\hline 13 & 0.734 & 0.530 & 0.933 & 0.888 & 0.708 & 0.967 \\
\hline 14 & 0.860 & 0.785 & 1.000 & 0.965 & 0.944 & 1.000 \\
\hline 15 & 0.809 & 0.720 & 1.000 & 0.788 & 0.644 & 0.919 \\
\hline 16 & 0.790 & 0.659 & 1.000 & 0.891 & 0.783 & 1.000 \\
\hline 17 & 0.781 & 0.676 & 1.000 & 0.810 & 0.716 & 1.000 \\
\hline 18 & 0.728 & 0.619 & 1.000 & 0.774 & 0.685 & 1.000 \\
\hline 19 & 0.806 & 0.715 & 1.000 & 0.726 & 0.637 & 1.000 \\
\hline 20 & 0.675 & 0.509 & 1.000 & 0.694 & 0.546 & 1.000 \\
\hline 21 & - & - & - & - & - & - \\
\hline 22 & 0.778 & 0.601 & 0.846 & 0.803 & 0.694 & 0.952 \\
\hline 23 & 0.880 & 0.863 & 1.000 & 1.000 & 1.000 & 1.000 \\
\hline 24 & - & - & - & 1.000 & 1.000 & 1.000 \\
\hline 25 & - & - & - & 0.982 & 0.948 & 1.000 \\
\hline Mean & 0.827 & 0.733 & 0.988 & 0.863 & 0.775 & 0.971 \\
\hline
\end{tabular}

\begin{tabular}{|c|c|c|c|c|c|}
\hline \multicolumn{3}{|c|}{2008} & \multicolumn{3}{|c|}{2009} \\
\hline Whole & Stage 1 & Stage? & Whole & Stage 1 & Stage 2 \\
\hline 0.713 & 0.585 & 1.000 & 0.695 & 0.548 & 0.920 \\
\hline 0.763 & 0.603 & 1.000 & 0.746 & 0.614 & 1.000 \\
\hline 0.804 & 0.725 & 1.000 & 0.899 & 0.825 & 1.000 \\
\hline 1.000 & 1.000 & 1.000 & 0.941 & 0.858 & 1.000 \\
\hline 0.751 & 0.643 & 1.000 & 0.714 & 0.587 & 0.928 \\
\hline 1.000 & 1.000 & 1.000 & 1.000 & 1.000 & 1.000 \\
\hline 1.000 & 1.000 & 1.000 & 1.000 & 1.000 & 1.000 \\
\hline 0.729 & 0.644 & 0.942 & 0.417 & 0.395 & 1.000 \\
\hline 0.967 & 0.948 & 1.000 & 1.000 & 1.000 & 1.000 \\
\hline 1.000 & 1.000 & 1.000 & 1.000 & 1.000 & 1.000 \\
\hline 1.000 & 1.000 & 1.000 & 0.999 & 0.998 & 1.000 \\
\hline 0.748 & 0.626 & 0.947 & 1.000 & 1.000 & 1.000 \\
\hline 0.956 & 0.828 & 0.999 & 0.956 & 0.826 & 0.998 \\
\hline 1.000 & 1.000 & 1.000 & 0.999 & 0.994 & 1.000 \\
\hline 0.921 & 0.864 & 1.000 & 0.990 & 0.971 & 1.000 \\
\hline 0.866 & 0.774 & 1.000 & 0.732 & 0.580 & 0.870 \\
\hline 0.840 & 0.761 & 1.000 & 0.806 & 0.700 & 1.000 \\
\hline 0.774 & 0.685 & 1.000 & 0.773 & 0.683 & 1.000 \\
\hline 0.872 & 0.778 & 1.000 & 0.784 & 0.655 & 1.000 \\
\hline 1.000 & 1.000 & 1.000 & 0.734 & 0.596 & 1.000 \\
\hline 1.000 & 1.000 & 1.000 & 1.000 & 1.000 & 1.000 \\
\hline 0.857 & 0.810 & 1.000 & 1.000 & 1.000 & 1.000 \\
\hline 0.734 & 0.638 & 0.760 & 0.720 & 0.627 & 0.745 \\
\hline 0.973 & 0.958 & 1.000 & 0.934 & 0.900 & 1.000 \\
\hline 0.826 & 0.655 & 1.000 & 0.901 & 0.789 & 1.000 \\
\hline 0.884 & 0.821 & 0.985 & 0.870 & 0.806 & 0.978 \\
\hline
\end{tabular}

The inefficiency rate, which is prevailing in the industry could be related to excess production capacity of the palm oil refineries in Malaysia. In 2009, the total production of CPO was about 17.6 million tons, of which 2.5 million tons were exported while the total capacity of refineries was 22.8 million tons in year 2009 .

\section{v. Conclusions}

In this paper, we investigated two-stage production systems with shared inputs and outputs where each stage has its own inputs and outputs in addition to the intermediate products. Then, we proposed a linear DEA approach, taking into account the series relationship among two stages, to measure the efficiency of the whole system and the efficiencies of two stages at the same time. Under the new framework, the overall efficiency of the system is illustrated as a convex combination of efficiencies of its two stages. Unlike Zha and Liang's approach, the proposed model can be applied to both CRS and VRS cases. The palm oil refineries in Malaysia, whose production process resembles the twostage process, are used to illustrate the proposed approach. The results show that the average efficiency rate of the industry in the period 2006 to 2009 is more than $80 \%$. The efficiency of the industry has increased from $83 \%$ in year 2006 to $88 \%$ in 2009.

\section{References}

[1] A. Amirteimoori, and M. Shafiei, Measuring the efficiency of interdependent decision making subunits in DEA. Appl. Math. Comput. 173(2) (2006), pp. 847-855.

[2] V. Bosetti, M. Cassinelli and A. Lanza, Using data envelopment analysis to evaluate environmentally conscious tourism management, The conference Tourism and Sustainable Development Chia, Sardegna, Italy, 2003.

[3] R.D. Banker, A. Charnes and W.W. Cooper, Models for estimating technical and scale inefficiencies in data envelopment analysis, Manage. Sci. 30 (1984), pp. 1078-1092.

[4] R. D. Banker, S. Janakiraman and R. Natarajan, Analysis of trends in technical and allocative efficiency: An application Texas public school districts, European J. Oper. Res. 154 (2004), pp. 477-491.

[5] A. Charnes and W.W. Cooper, Programming with linear fractional functional, Naval Res. Logist. Quarterly, 15 (1962), pp. 333-334.

[6] A. Charnes, W.W. Cooper and E. Rhodes, Measuring the efficiency of decision making units, European J. Oper. Res. 2 (6) (1978), pp. 429444.

[7] Y. Chen and J. Zhu, Measuring information technology's indirect impact on firm performance, Inform. Technol. Manage. J. 5(1-2) (2004), pp. 9-22.

[8] Y. Chen, W.D. Cook, N. Li and J. Zhu, Additive efficiency decomposition in two stage DEA, European J. Oper. Res. 196 (2009), pp. 1170-1176.

[9] T.J. Coelli, D.S. Rao, C.J. O’Donnell, and G.E. Battese, An Introduction to Efficiency and Productivity Analysis, second edition, Springer, New York, New Jersey, 2002.

[10] K. Cullinane, P. Ji and T.f. Wang, The relationship between privatization and DEA estimates of efficiency in the container port industry, Journal of Economics and Business, 57 (2005), pp. 433-462.

[11] C. Kao and S.N. Hwang, Efficiency decomposition in two-stage data envelopment analysis: An application to non-life insurance companies in Taiwan, European J. Oper. Res. 185 (1) (2008), pp. 418-429.

[12] L.M. Seiford and J. Zhu, Profitability and marketability of the top 55 US commercial banks, Manage. Sci. 45 (9) (1999), pp. 1270-1288.

[13] T.R. Sexton and H.F. Lewis, Two-stage DEA: An application to major league baseball, J. Productiv. Anal. 19 (2003), pp. 227-249.

[14] Wang, Y. M. and K.S. Chin, Some alternative DEA models for twostage process, Expert Syst. Appl. 37 (2010), pp. 8799-8808.

[15] Y. Zha, and L. Liang, Two-stage cooperation model with input freely distributed among the stages, European J. Oper. Res. 205 (2) (2010), pp. 332-338.

[16] J. Zhu, Multi-factor performance measure model with an application to Fortune 500 companies, European J. Oper. Res. 123(1) (2000), 105-124. 